\title{
Effect of Ocean Currents and Temperature Variability on Yellowfin Tuna Catch Rates of Sri Lankan Longline Fishery
}

\author{
Maddumage Upeksha Swarnamalie ${ }^{1,} J_{a g a t h}$ Rajapaksha $^{2}$, Jagath Gunatilake ${ }^{1,3}$ \\ ${ }^{1}$ Postgraduate Institute of Science, University of Peradeniya, P.O. Box 25, Peradeniya, Sri Lanka. \\ ${ }^{2}$ Department of Oceanography, The Ocean University of Sri Lanka, Colombo 15, Sri Lanka. \\ ${ }^{3}$ Department of Geology, University of Peradeniya, Peradeniya. \\ DOI: 10.29322/IJSRP.11.08.2021.p11662 \\ http://dx.doi.org/10.29322/IJSRP.11.08.2021.p11662
}

\begin{abstract}
Duration of Sri Lankan fishing fleets has been reported as 2-4 weeks to catch the average target of approximately 2 tones per trip. However, low catch rates are caused by the uncertainty of catches due to lack of technology available to find fishing grounds. This study is focused on the impact of temperature and ocean currents at the depth where Yellowfin tuna (YFT) has been caught. Currents and temperature data at different depth levels were obtained from Copernicus Marine Environment Monitoring Service (CMEMS). Longline tuna catch datasets were obtained from the Department of Fishery, Sri Lanka. The catch datasets were gridded into 0.25 -degree spatial resolution to overlay with the oceanographic parameters such as temperature in the same resolution. The fishery and oceanographic datasets were composited in to 5-day intervals for data overlay and matching. The matched dataset was analyzed using R-statistical packages. Empirical cumulative distribution function (ECDF) was applied to identify the nature of the relationships between catch per unit effort (CPUE) and the relationship with the two oceanographic parameters were proved by the generalized additive model (GAM). The results showed that YFT prefers warmer waters, above $24^{\circ} \mathrm{C}$, particularly fished at the temperature between $22.0-27.0^{\circ} \mathrm{C}$ and current speed less than $0.4 \mathrm{~ms}^{-1}$, peak around $0.25 \mathrm{~ms}^{-1}$. The result of the study also confirms that tuna is more likely to be aggregated at the depth of $60-75 \mathrm{~m}$. The YFT fishable aggregations can be found in the above temperature ranges which occur at different depths depending on the seasonal monsoon. Thus, the spatial distribution of YFT is varying depending on the prevailing oceanographic conditions. These results are based on the Sri Lankan longline which has maximum depth penetration is about $120 \mathrm{~m}$.
\end{abstract}

Index Terms- Indian Ocean, CPUE, Vertical Temperature, Isotherms, Temperature Fluctuations, Sri Lankan Dome

\section{INTRODUCTION}

$\mathrm{S}$ ri Lanka is one of the oldest and most important tuna producing islands in the Indian Ocean. Exploration of tuna fishery resources around this island have shown that tuna resources of Sri Lanka are mainly Yellowfin tuna (YFT) (Thunnus albacares), Bigeye tuna (Thunnus obsesus), Skipjack tuna (Katsuwonus pelamis), Kawakawa (Enthynnus affinis), Frigate tuna (Auxis thazard) and Bullet tuna (Auxis rochei) (Jayasooriya et al., 2013). Yellowfin tuna is a premium export product to Japan, Europe, and North America which is widely used in raw fish dishes, especially sashimi (Lecomte et al., 2017). Yellowfin tuna are known to be highly migratory and widely distributed in the ocean (Zagaglia et al., 2004). The wide distribution of YFT makes the search for this resource time consuming and costly. The search can be made more efficient and less costly by predicting the areas where fish aggregate in space and time (Rajapaksha, 2009).

Sri Lanka's longline fishery operates within its exclusive economic zone (EEZ) 200 miles known as offshore fishery and high seas fishery beyond mainly Bay of Bengal and southern areas of the Island. However, high seas fishing operates in Arabian Sea mainly for Skipjack tuna by gillnets. In oceanographic point of view, Sri Lanka is located in a unique place in between Arabian sea and Bay of Bengal, having strong seasonal currents transporting water with different properties between the two by monsoon winds (De Vos et al., 2014). This causes characteristic seasonality of temperature, phytoplankton, ocean currents and mixed layer properties. Temperature is the most important parameter for locating tuna resources. Temperature structure of the ocean is essential information to deploy fishing lines in appropriate depth where tuna fish aggregations occur. The subsurface temperature is influenced by mixing rates due to wind forcing and the fish aggregating depths are changed as fish schools are very sensitive to the ambient temperature. Therefore, temperature variability in the water column and hooking depth is influential to the catch rates in space and time (Rajapaksha, 2014).

Ocean currents also have profound impacts on marine life, moving not only animals and plants around the ocean but also redistributing heat and nutrients (Hays, 2017). Surface currents are a significant part of the global ocean circulation and they can influence many oceanographic features such as temperature, salinity, concentration of suspended mattes and the supply of nutrients including phytoplankton and zooplankton. Fish movements are associated with ocean currents and the availability of food in different areas at different time. Thus, the ocean features such as current speed and direction, horizontal and vertical temperatures This publication is licensed under Creative Commons Attribution CC BY. 
structures and the dynamic relationships influenced between ocean and atmosphere can be analyzed to generate supportive information for fishing.

Uses of remote sensing satellite data obtained from various platforms provide several advantages including the opportunity to get a wide synoptic coverage and repeated regular sampling to produce time series for many years long (Rajeesh and Dwarakish, 2015). Remote sensing techniques show great potential to support successful exploitation of pelagic fishery resources and global fisheries management. Many types of fish migrate on a regular basis, on time scales ranging from daily to annually or even longer and distances ranging from a few kilometers to thousands of kilometers. Fish tend to aggregate in ocean areas that exhibit conditions favored by specific fish species. Some of the relevant oceanographic conditions, such as sea surface temperature, ocean color (productivity) and oceanic fronts, which strongly influence natural fluctuations of fish stocks, can be observed and measured by remote sensors on satellites and aircraft. The remotely sensed data is provided in near-real time that helps fishermen to save fuel, fishing duration and search time. The modelers who produce fisheries forecasts help scientists who develop strategies for sustainable fisheries management (Klemas, 2013).

\section{MATERIALS AND METHODS}

The study was carried out by combining ocean observations made from remote sensing satellite products, consisting temperature and currents together with tuna catch records on logbooks which was obtained from the Department of Fisheries for the period of two years (2018 - 2019). The fishery data consisted of information on fishing date, boat registration number, fishing location (latitude, longitude), number of hooks and species wise catch. Those data was uploaded to the database and necessary datasets were recalled using $\mathrm{R}$ software and gridded into 0.25 -degree resolution to overlay with oceanographic data to match with temperature and current data at appropriate fishing depths. There are many factors that determine the likelihood of a particular hook catching a fish, including the depth of hook, bait type, availability of live food, timing and location of effort ( Rajapaksha et al., 2013).

Satellite data products were obtained from the Copernicus Marine Environment Monitoring Service (CMEMS) which is the marine component of the Copernicus program of the European Union. The Copernicus satellite constellation is known as Sentinel. Sentinel 3, a pair of oceanography satellites carry multi-payload packages to provide ocean observation data and land optical observation products. CMEMS, instantaneous hourly fields for sea surface height, sea surface temperature and surface currents are also provided (Copernicus Marine Environment Monitoring Service). The data used in this study was in daily composts of 0.25 -degree spatial resolution. Parameters contained in the datasets were date, latitude and longitude, northward current velocity in the water column, eastward current velocity, temperature and the depth in the water column. Fishery and oceanographic data was overlaid in $0.25-$ degree resolution and 5-day composites. Catch per unit of effort was calculated as $\mathrm{kg} / 100 \mathrm{hooks} /$ day. The fishery data was overlaid on the corresponding 5-day composites of satellite images. The output records of data matching consisted of fishing locations, catch rates with corresponding oceanographic parameters, temperature and currents (Rajapaksha et al., 2013). All the statistical analyses were performed using R software with various packages (Gomez-Rubio, 2018).

To describe the relationship between oceanographic conditions of temperature, currents and YFT CPUE, this study first used histogram graphs of high catch data. Secondly, this study analyzed the stronger association between all the oceanographic variables and YFT CPUE high catch data using empirical cumulative distribution function (ECDF) analysis. This analysis used three functions as follows (Andrade and Garcia, 1999 ; Zainuddin, 2011),

$\mathrm{f}(\mathrm{t})=\frac{1}{\mathrm{n}} \sum_{\mathrm{i}=1}^{\mathrm{n}} \mathrm{l}\left(\mathrm{x}_{\mathrm{i}}\right)$

With the indication function

$1\left(x_{i}\right)= \begin{cases}1 & \text { if } x_{i} \leq 1 \\ 0 & \text { otherwise }\end{cases}$

$g(t)=\frac{1}{n} \sum_{i=1}^{n} \frac{y_{i}}{\bar{y}} l\left(x_{i}\right)$

$D(t)=\max |f(t)-g(t)|$

where, $\mathrm{f}(\mathrm{t})$ : empirical cumulative frequency distribution function, $\mathrm{g}(\mathrm{t})$ : catch-weighted cumulative distribution function, $\mathrm{l}(\mathrm{xi})$ : indication function and $\mathrm{D}(\mathrm{t})$ : absolute value of the difference between two curves $\mathrm{f}(\mathrm{t})$ and $\mathrm{g}(\mathrm{t})$ at any point $\mathrm{t}$ and assessed by standard Kolmogorov-Smirnov test, $\mathrm{n}$ : the number of fishing trips, $\mathrm{xi}$ : the measurement for satellite-derived oceanographic variables in a fishing trip $\mathrm{i}, \mathrm{t}$ : an index, ranging the ordered observations from lowest to highest value of the oceanographic variables, yi : the CPUE obtained in a fishing trip i, and the estimated mean of CPUE for all fishing trips. The coordinate labeled "max" represents the specific value of the variables at which the difference between the two curves $(|g(t)-f(t)|)$ was maximum.

Generalized additive model (GAM) was applied to identify the nature of relationships between CPUE and the oceanographic parameters. The relationships between two variables and the CPUE are mostly non-linear. GAM is a non-parametric generalization 
ISSN 2250-3153

of multiple linear regressions which is less restrictive in assumptions of the underlying statistical data distribution. The GAM has no analytical form but explain the variance of CPUE more effectively and flexibly (Rajapaksha et al., 2013).

$\ln ($ CPUE $)=a+s($ Temperature $)+s($ Velocity $)+s($ lat $)+s($ lon $)+e$

Where a: is a constant, $\mathrm{s}$ : is a spline smoothing function of the variables (temperature, current velocity, latitude and longitude) and $\mathrm{e}$ : is a random error term. A GAM is a flexible nonparametric technique that can be used to model complex relations between a response variable and independent variables. Functions are fitted between a number of breakpoints (knots) along the independent variable range, in general using cubic polynomials (or cubic splines) and these functions are then smoothly joined to form the final curve. There is no priori assumption about the functional form of the relationship. The trade-off between fidelity to the data and smoothness of the fitted curve can be regulated automatically or manually. The curve can be automatically fitted by estimating a smoothing parameter and thereby the number of knots and degrees of freedom minimizing the generalized cross validation score. Alternatively, the number of knots can be fixed manually (Wood, 2001).

\section{RESULTS}

The CPUE distribution of YFT with respect to the associated water temperature shows left skewed and maximum catch rates falls within $22.0-27.0^{\circ} \mathrm{C}$. On the contrary, CPUE distribution in relation to the water currents shows a right skewed and high catch rates falls within $0.2-0.4 \mathrm{~ms}^{-1}$, (Figure 1).
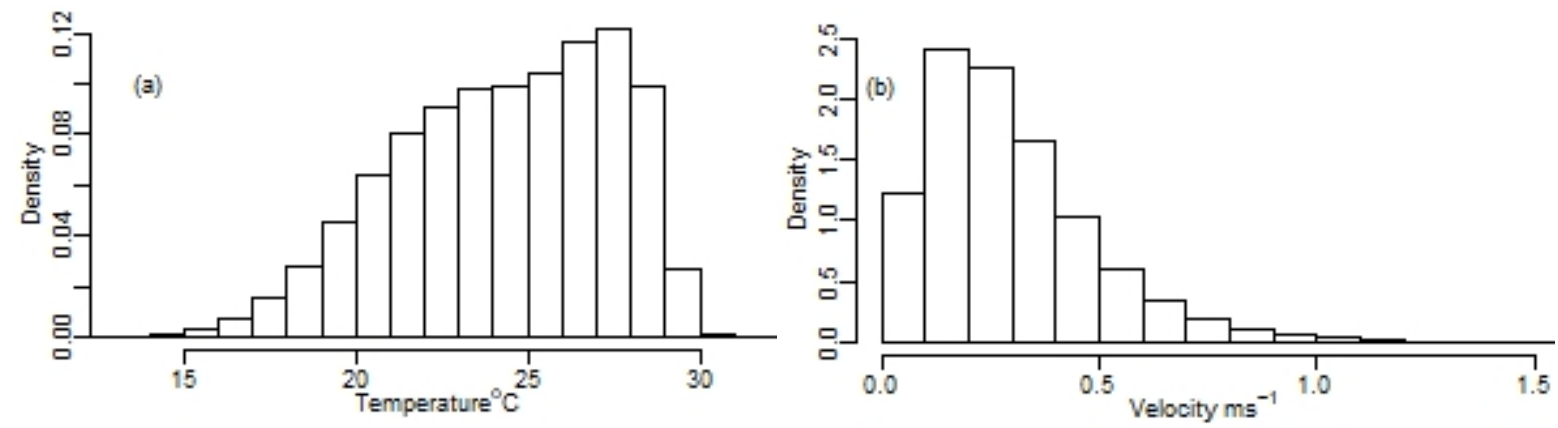

Figure 1: Histograms showing density of Yellowfin tuna caught with temperature (a) and current velocity (b).

The cumulative distribution curves of the variables are different and the degrees of the difference between two curves (D (t)) are statistically significant $(\mathrm{P}<0.01)$. The results showed a stronger association between CPUE and the variables, temperature ranging between 22 to $27.0^{\circ} \mathrm{C}$ and current speed less than $0.4 \mathrm{~ms}^{-1}$. The strongest associations between CPUE and the variables occurred around $25^{\circ} \mathrm{C}$ temperature and around $0.25 \mathrm{~ms}^{-1}$ current speed.

GAM results showed that all environmental factors are in a significant level $(\mathrm{p}<0.01)$ and influence the average catch rates of YFT. The result showed that the temperature, current and the location (latitude, longitude) has the minimum generalized cross-validation (GCV) score of 0.1387 and highest deviance of $2.58 \%$ ( $p<0.001)$ which is the best predictor explained the density of YFT aggregation (Table 1).

Table 1: GAM result summary.

\begin{tabular}{|l|c|c|c|}
\hline Parameter & $\%$ Deviance & GCV score & P Value \\
\hline Temperature & 0.432 & 0.1417 & $<0.001$ \\
\hline Current Velocity & 0.081 & 0.1422 & $<0.001$ \\
\hline Temp+Velocity+lat+lon & 2.58 & 0.1387 & $<0.001$ \\
\hline
\end{tabular}



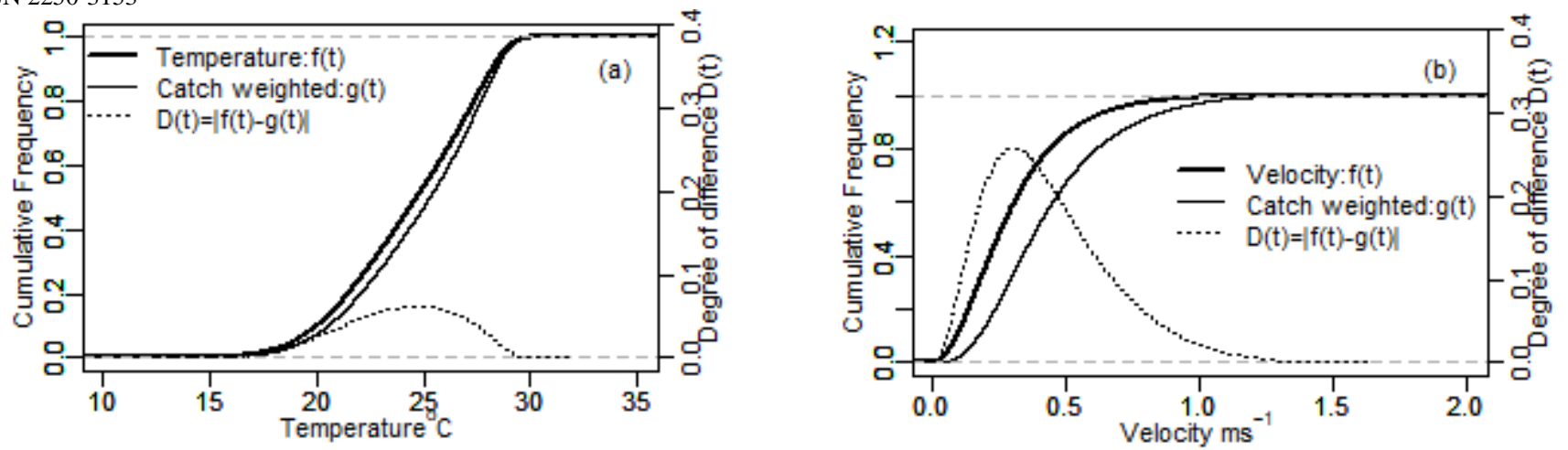

Figure 2: (a) Empirical cumulative distribution frequencies of temperature of Yellowfin tuna catch weighted. (b) Empirical cumulative distribution frequencies of current velocity of Yellowfin tuna catch weighted. The dashed lines show the degree of differences between the two curves.
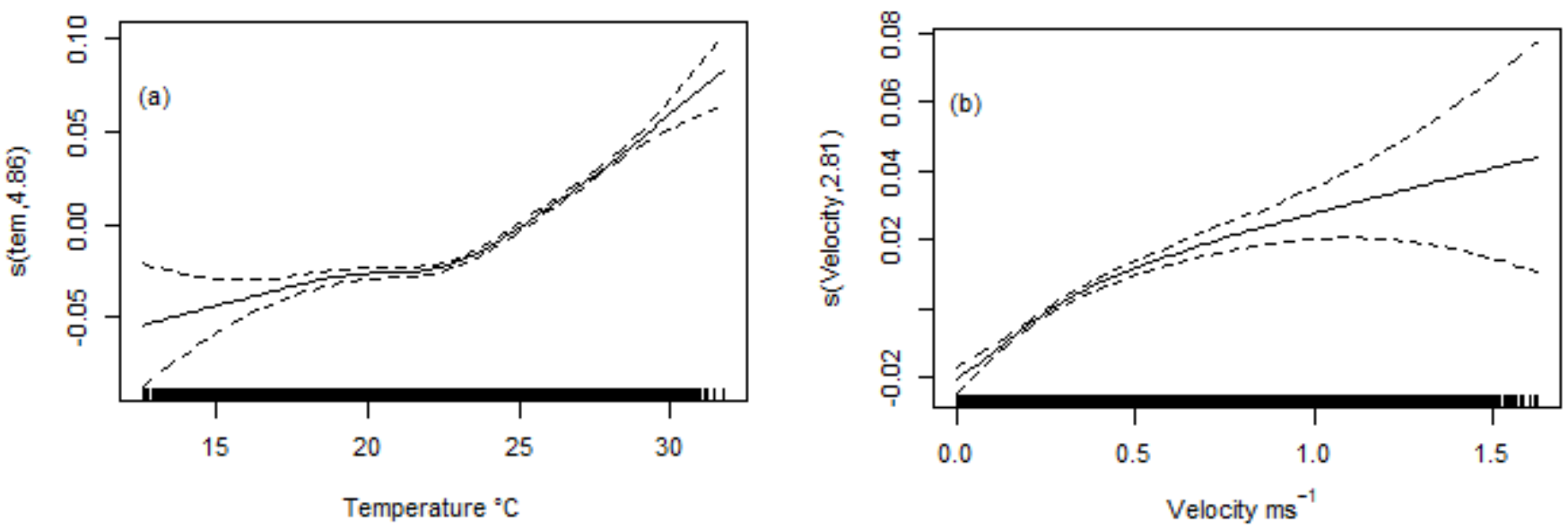

Figure 3: (a) Generalized Additive Model (GAM) derived the effect of temperature on Yellowfin tuna CPUE (log transformed).

(b) Generalized Additive Model (GAM) derived the effect of current velocity on Yellowfin tuna CPUE (log transformed).

Dashed lines indicate $95 \%$ of the confidence intervals. The relative density of data points is shown in rug plots along the $\mathrm{x}$-axis.

Catch overlay maps for YFT were generated using monthly averaged temperature and CPUE data based on four categories as follows,

$\begin{array}{ll}1 & 0 \leq \text { CPUE }<50 \\ 2 & 50 \leq \text { CPUE }<100 \\ 3 & 100 \leq \text { CPUE }<150 \\ 4 & 150 \leq \text { CPUE }\end{array}$

Sri Lankan tuna longline fishery distributes within the EEZ, as well as in international waters in the Indian Ocean (Rathnasuriya et al., 2016). The tuna longline activities mainly concentrated to the northeastern waters and the southwestern part of the country. The YFT fishable aggregations are available in the area throughout the year although the spatial distribution of YFT is varying depending on the prevailing oceanographic conditions (Rajapaksha et al, 2013). Sri Lankan longlines operates in shallower depths due to lower capacity of fleets and onboard manpower for hand-hauling the fishing lines. The shallow depth of tuna existence can be considered as feeding grounds. Longlines are operating comparatively deeper waters in the south of Sri Lanka (Rajapaksha et al., 2013). As the depth increases, YFT can be found at low temperature ranges. The result shows that YFT is more likely to be aggregated at the depth range from $60-75 \mathrm{~m}$ in the ocean. 

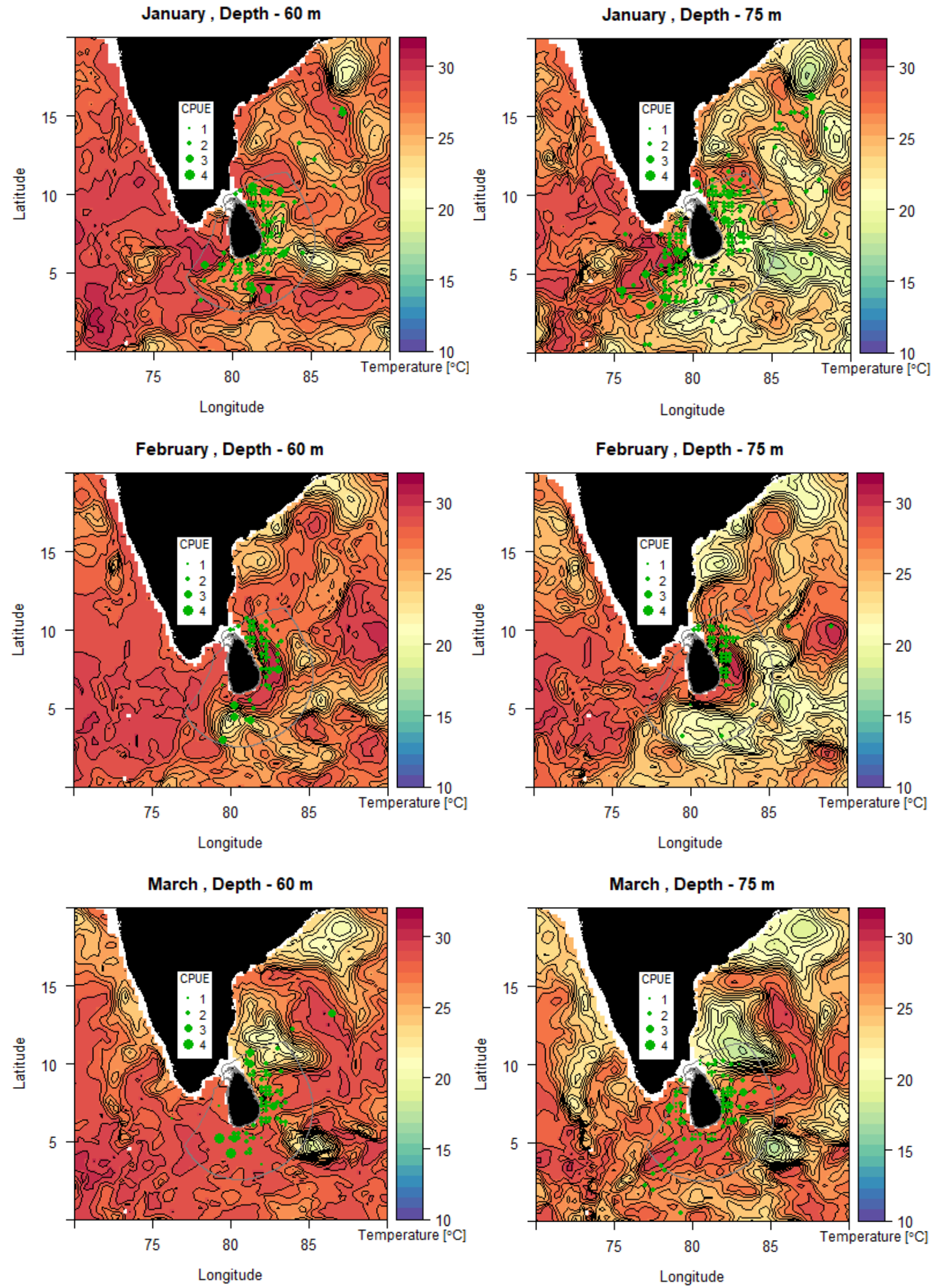

Figure 4: Monthly mean catch overlay (solid green circles) on monthly mean temperature at $60 \mathrm{~m}$ and $75 \mathrm{~m}$ depths from January - March 2019. 

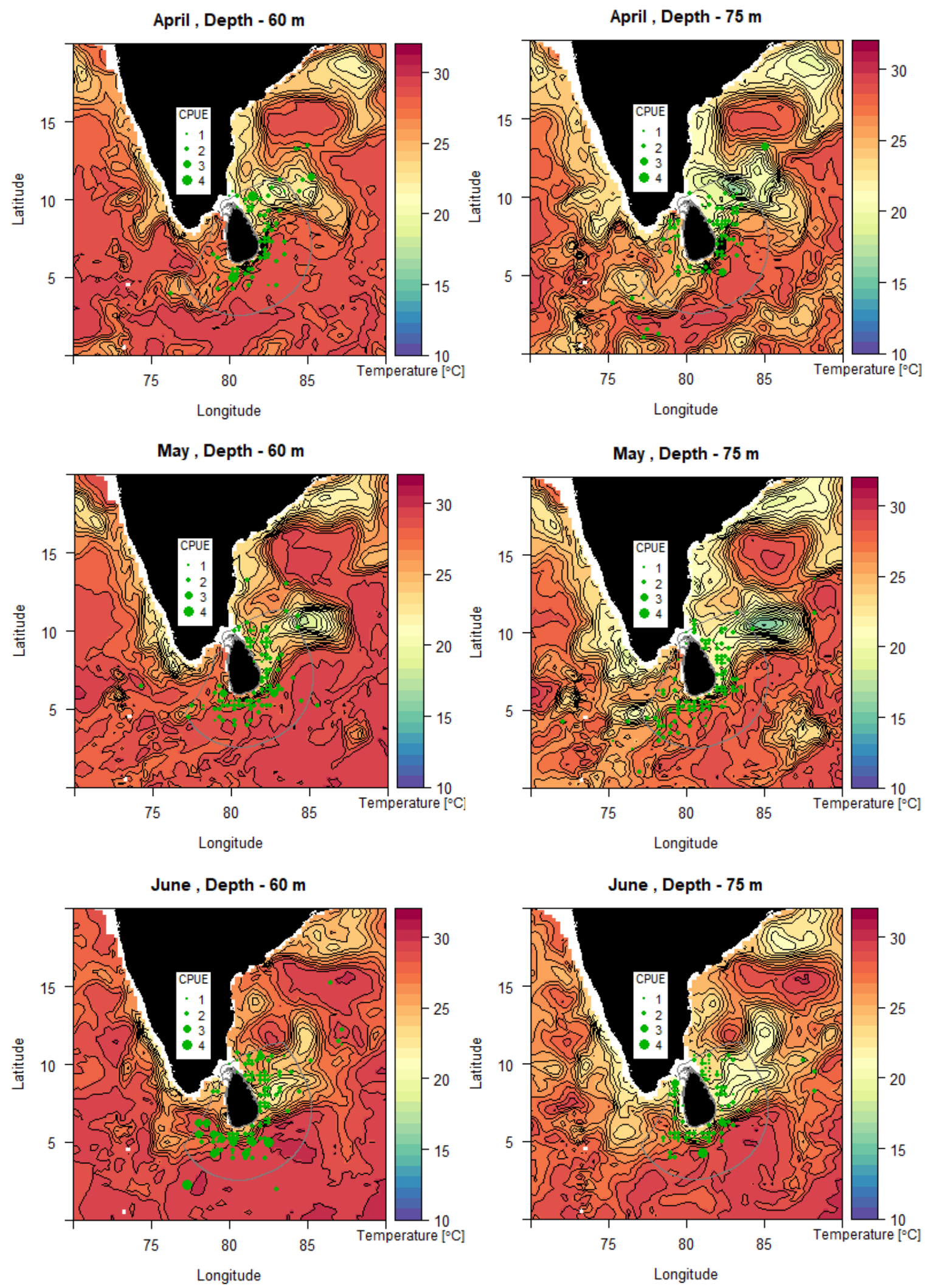

Figure 5: Monthly mean catch overlay (solid green circles) on monthly mean temperature at $60 \mathrm{~m}$ and $75 \mathrm{~m}$ depths from April June 2019. 

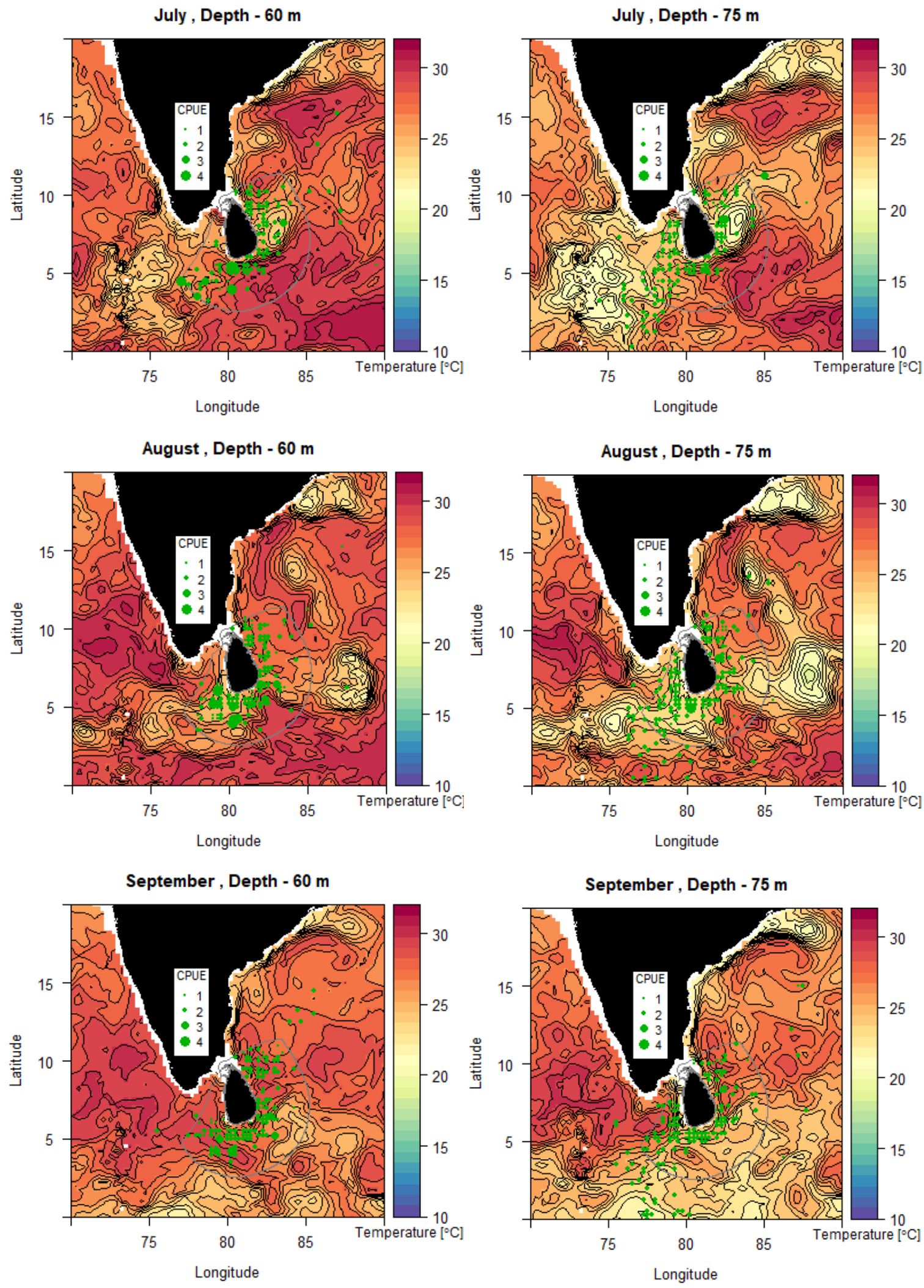

Figure 6: Monthly mean catch overlay (solid green circles) on monthly mean temperature at $60 \mathrm{~m}$ and $75 \mathrm{~m}$ depths from July September 2019. 

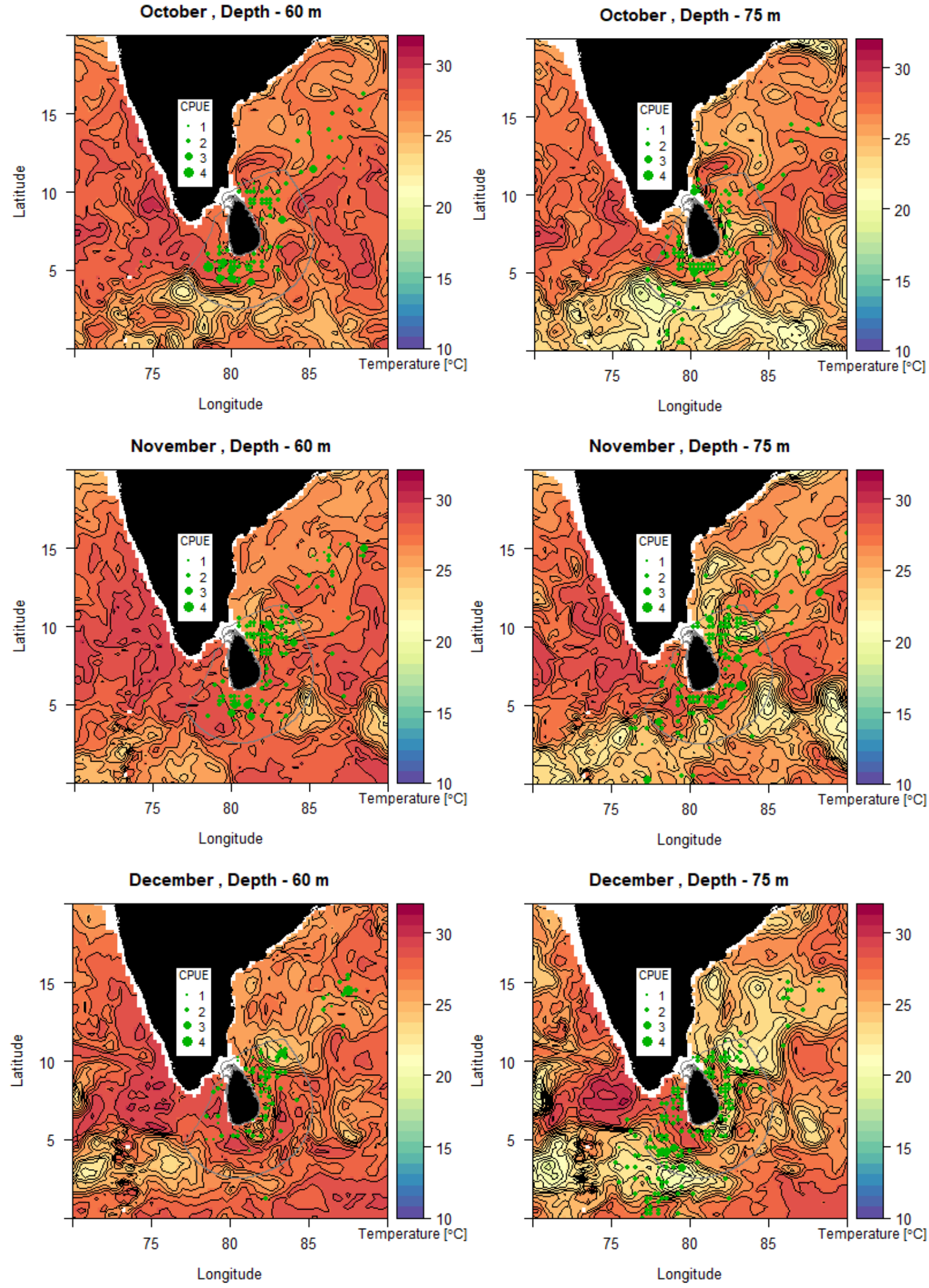

Figure 7: Monthly mean catch overlay (solid green circles) on monthly mean temperature at $60 \mathrm{~m}$ and $75 \mathrm{~m}$ depths from October - December 2019. 
(a) Coordinates $(5,77)$

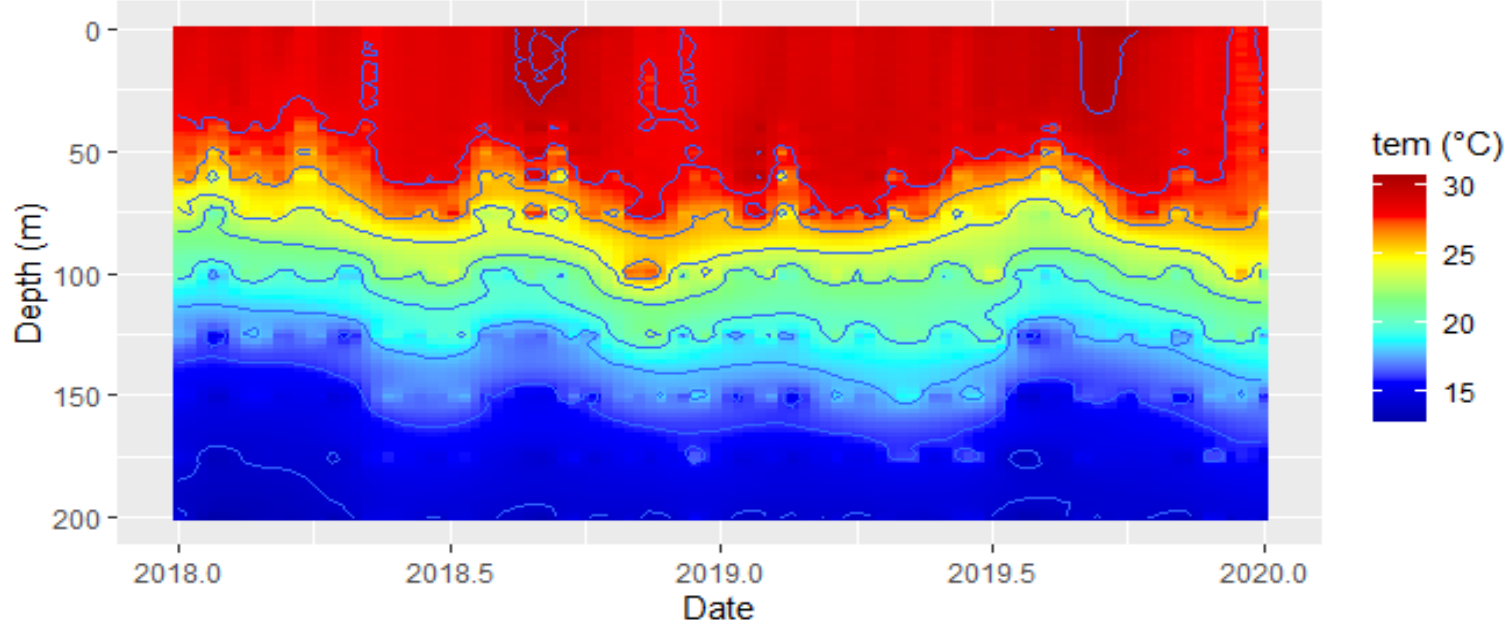

(b) Coordinates $(15,87)$

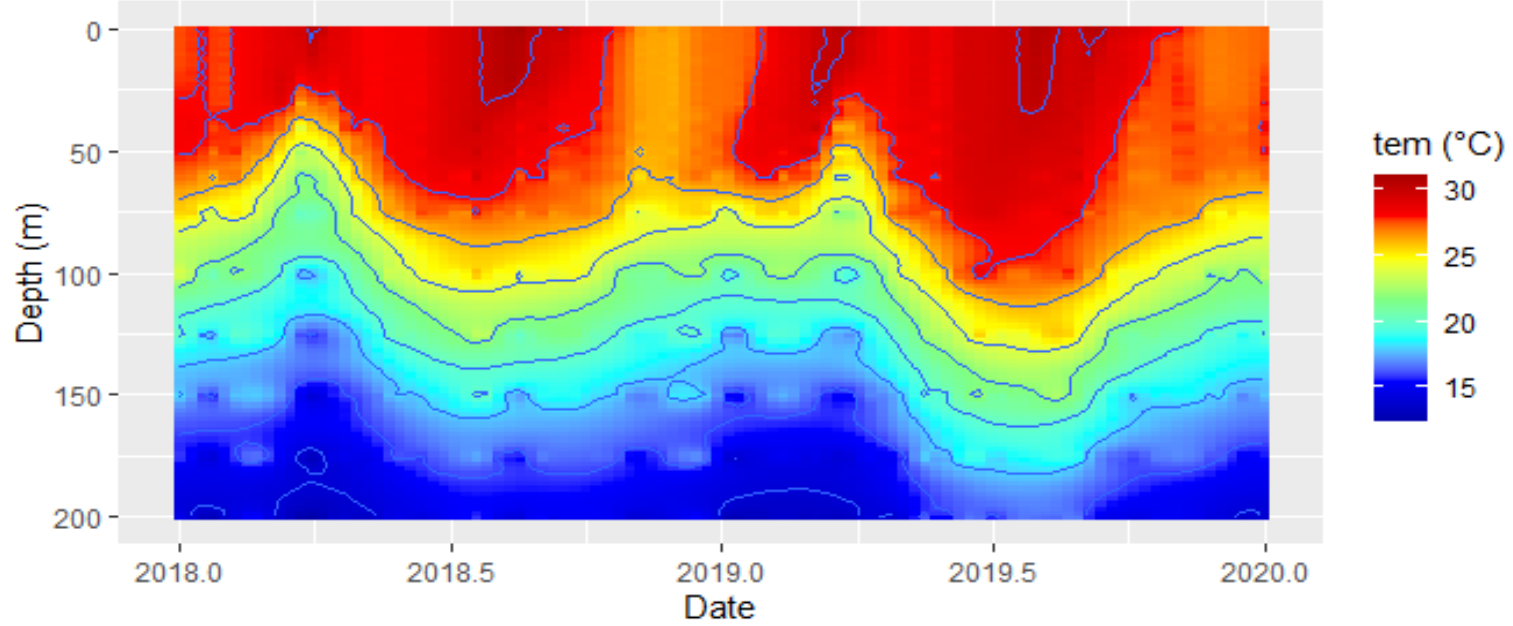

(c) Coordinates $(6,83)$

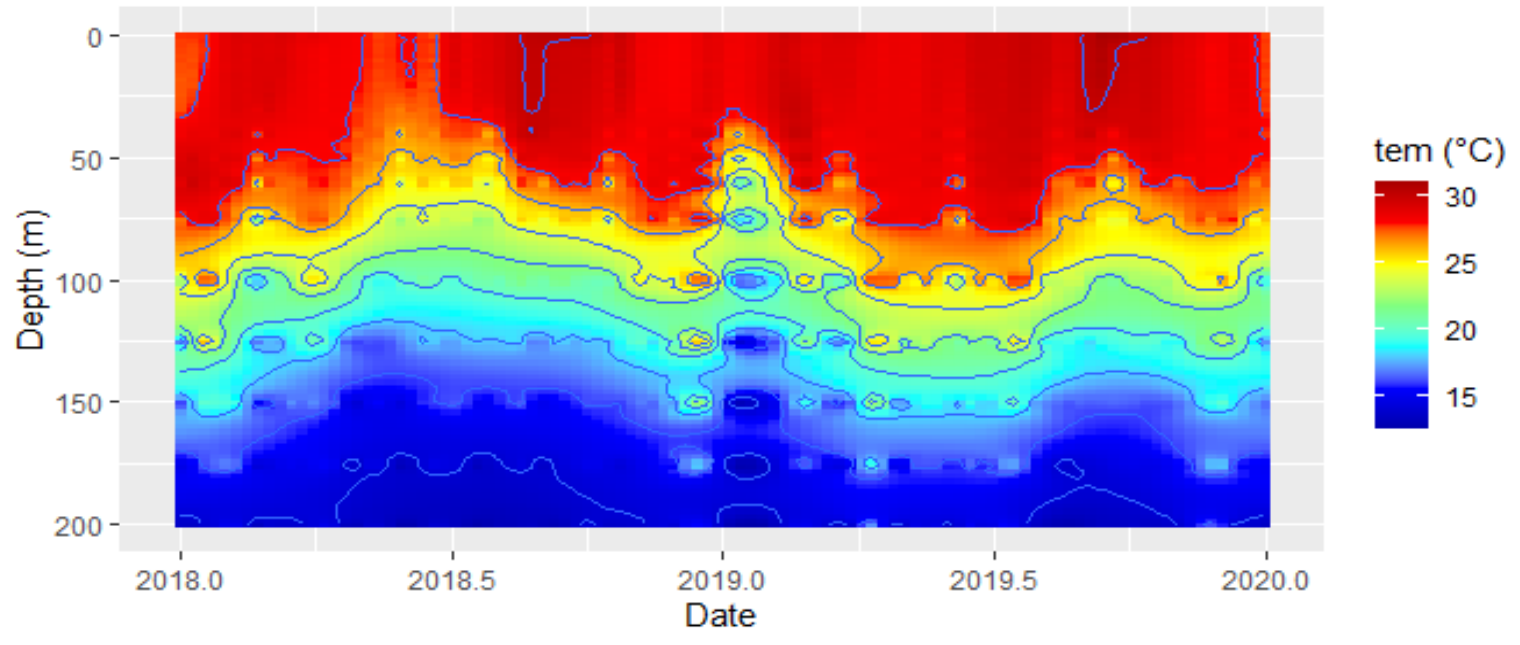

Figure 8: Time series of temperature vertical profile for two years (2018-2019) at locations a,b and c. showing seasonal variability of isotherms depth.

Figure 8, illustrates that the three places have different seasonal temperature fluctuations. The shape and seasonal variation of the vertical temperature vary with the latitude. Sri Lanka is influenced by two monsoon seasons (Northeast and Southwest) and two inter monsoonal periods (De Vos et al., 2014). Typically southwest monsoon occurs during May to September and northeast monsoon occurs from December to February ( Department of Meterology, Sri Lanka). During the southwest monsoon, warmer surface water mass moves form Arabian Sea towards east and deeper colder water mass moves to north. During the northeast monsoon, deeper colder water mass moves along the East Indian coat across the island. In both seasons the warmer surface water penetrates more than $75 \mathrm{~m}$ deep. The presence of land also increases the yearly temperature variations (Henrik and Aas, 2012). For instance, the Asian land mass completely isolates the Indian Ocean from the Arctic Ocean. The Indian Ocean is different from the 
Atlantic and the Pacific in that at $20^{\circ} \mathrm{N}$ it is bordered by the Asian continent. Therefore the wind conditions and resulting surface currents and affect the ocean temperature, will be partly dominated by the land climate.

(a) 2018-01-30, Depth - $60 \mathrm{~m}$

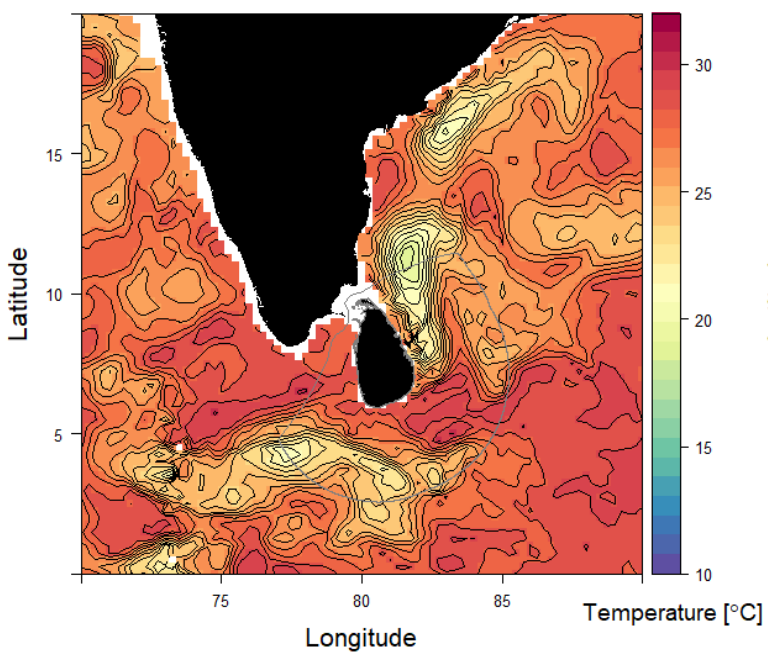

(b) 2018-01-30, Depth - 75 m

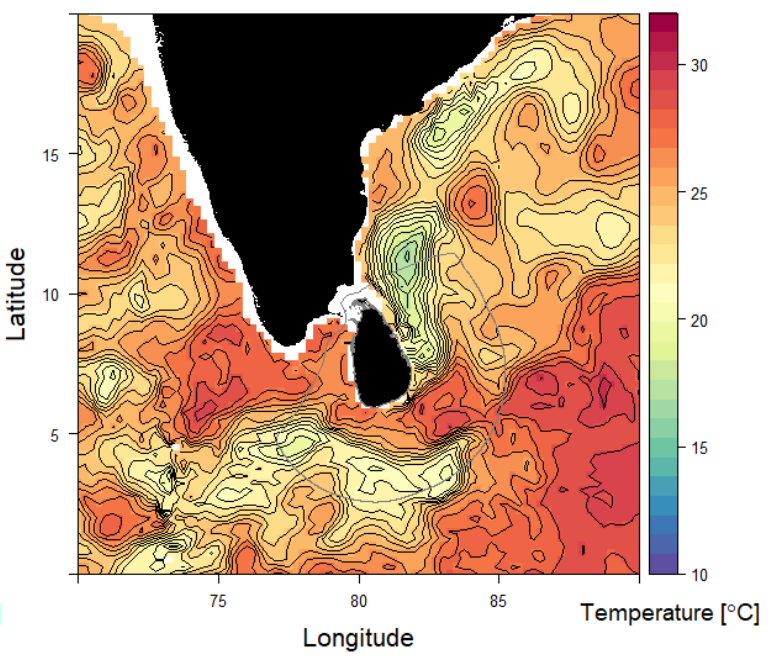

Figure 9: Temperature maps during the northeast monsoon at $60 \mathrm{~m}$ and $75 \mathrm{~m}$ depths.

(a) 2018-06-30, Depth - $60 \mathrm{~m}$

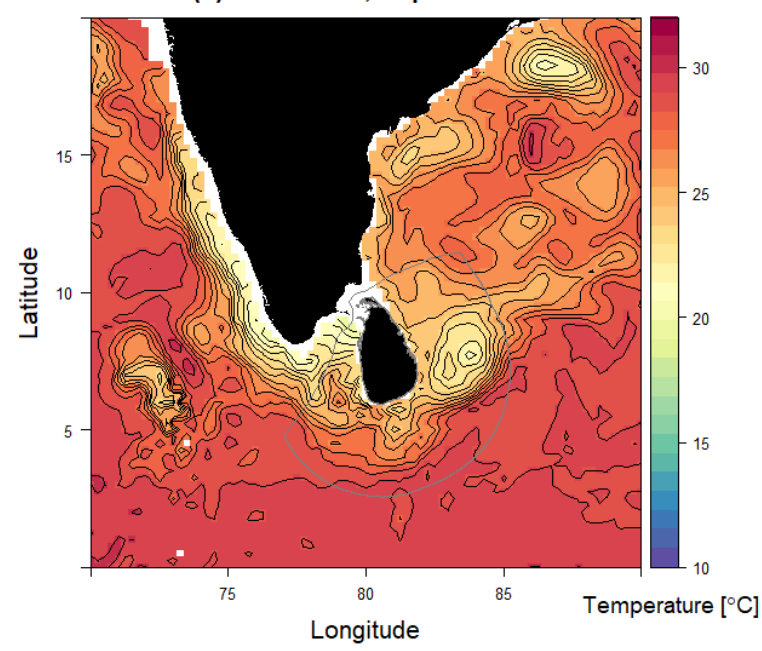

(b) 2018-06-30, Depth - $75 \mathrm{~m}$

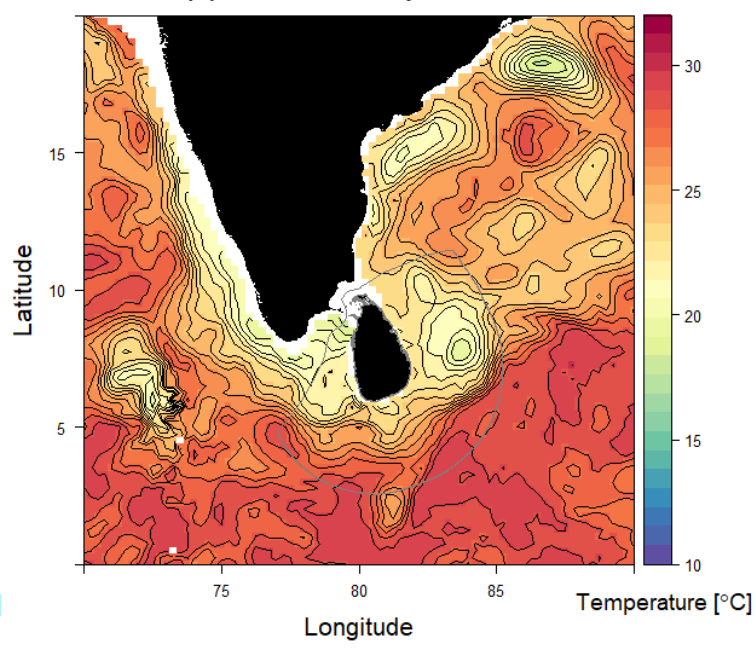

Figure 10: Temperature maps during the southwest monsoon at $60 \mathrm{~m}$ and $75 \mathrm{~m}$ depths.

The monsoon is a seasonal change of wind direction which affect the current direction too. Southwest monsoon currents flows from west to east and the northeast monsoon currents flow from east to west. The monsoon drift is shallow during the northeast monsoon period and will generally have a minimal effect on the waters below the thermocline (De Vos et al., 2014). The northeast monsoon is a gentle phenomenon, with low chlorophyll concentrations and moderate to high temperature values in the northern waters and rest of the oceanic region around Sri Lanka. During the southwest monsoon high chlorophyll patches develop in the south and southeast coasts as a result of upwelling phenomenon. These chlorophyll rich upwelling areas create good fishing grounds (Yapa, 2011). 
(a) Date: 2018-01-30, Depth: $60 \mathrm{~m}$

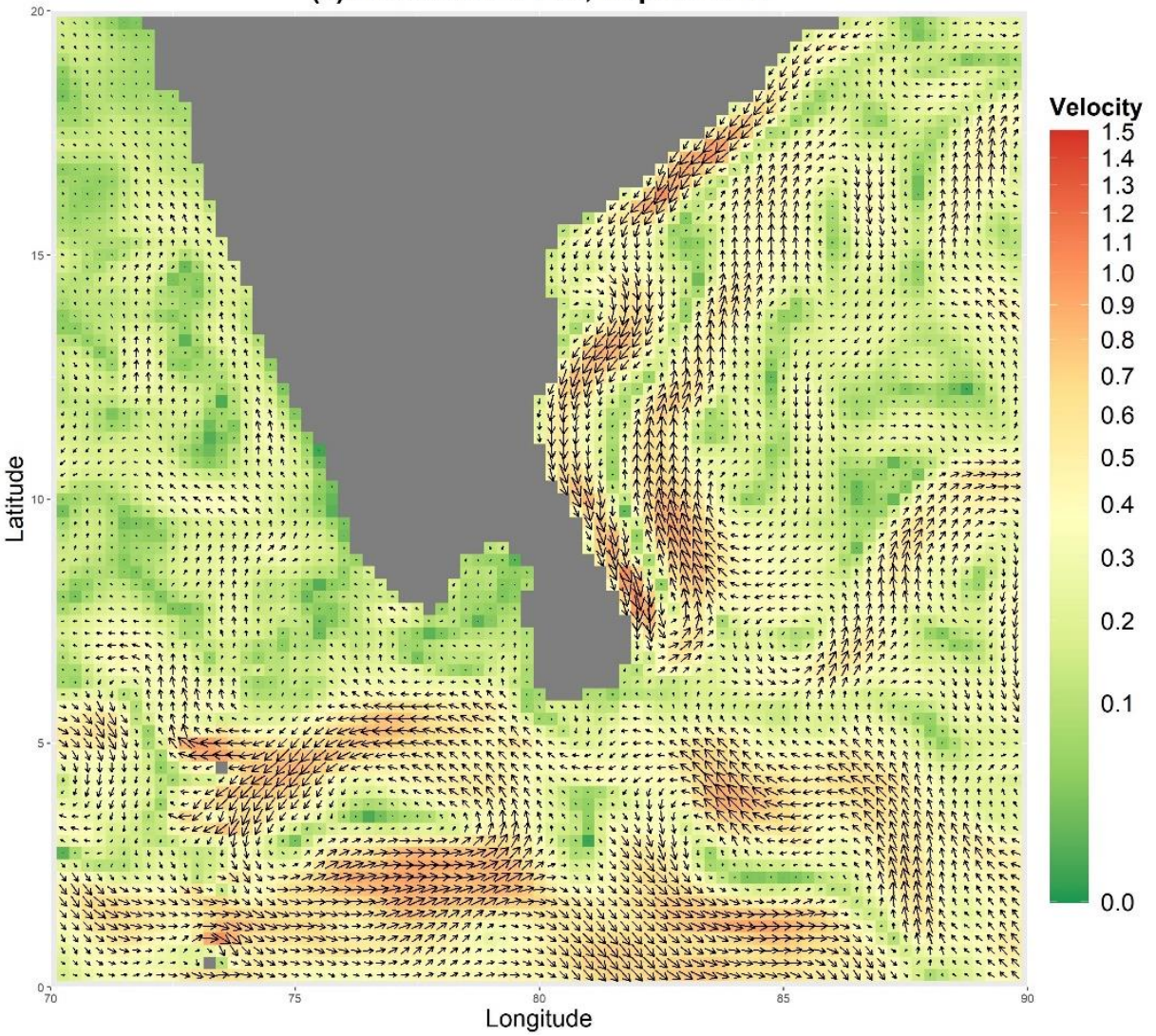

(b) Date: 2018-01-30, Depth: $75 \mathrm{~m}$

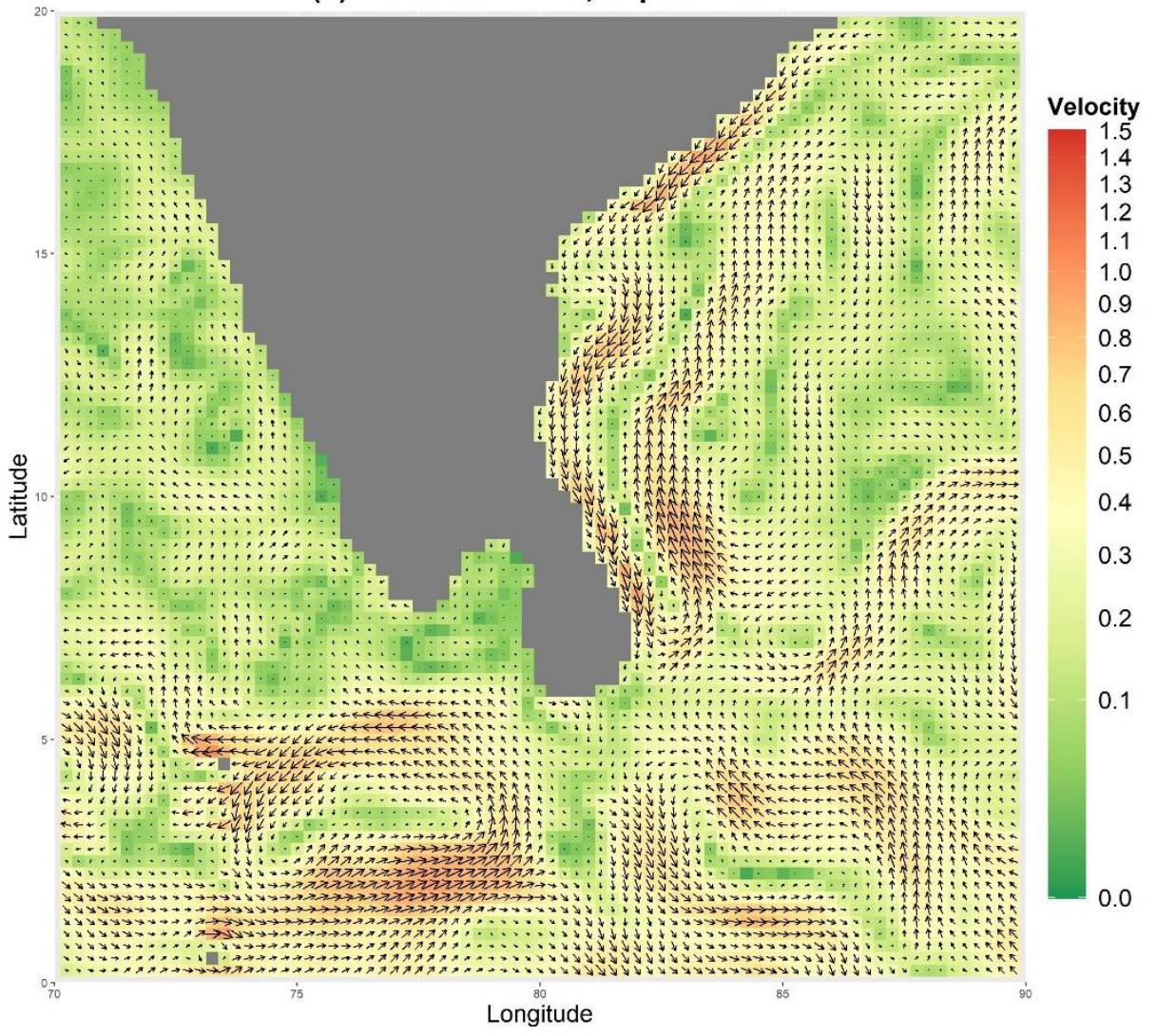

Figure 11: Current maps during the northeast monsoon at $60 \mathrm{~m}$ and $75 \mathrm{~m}$ depths. 
(a) Date: 2018-06-30, Depth: $60 \mathrm{~m}$

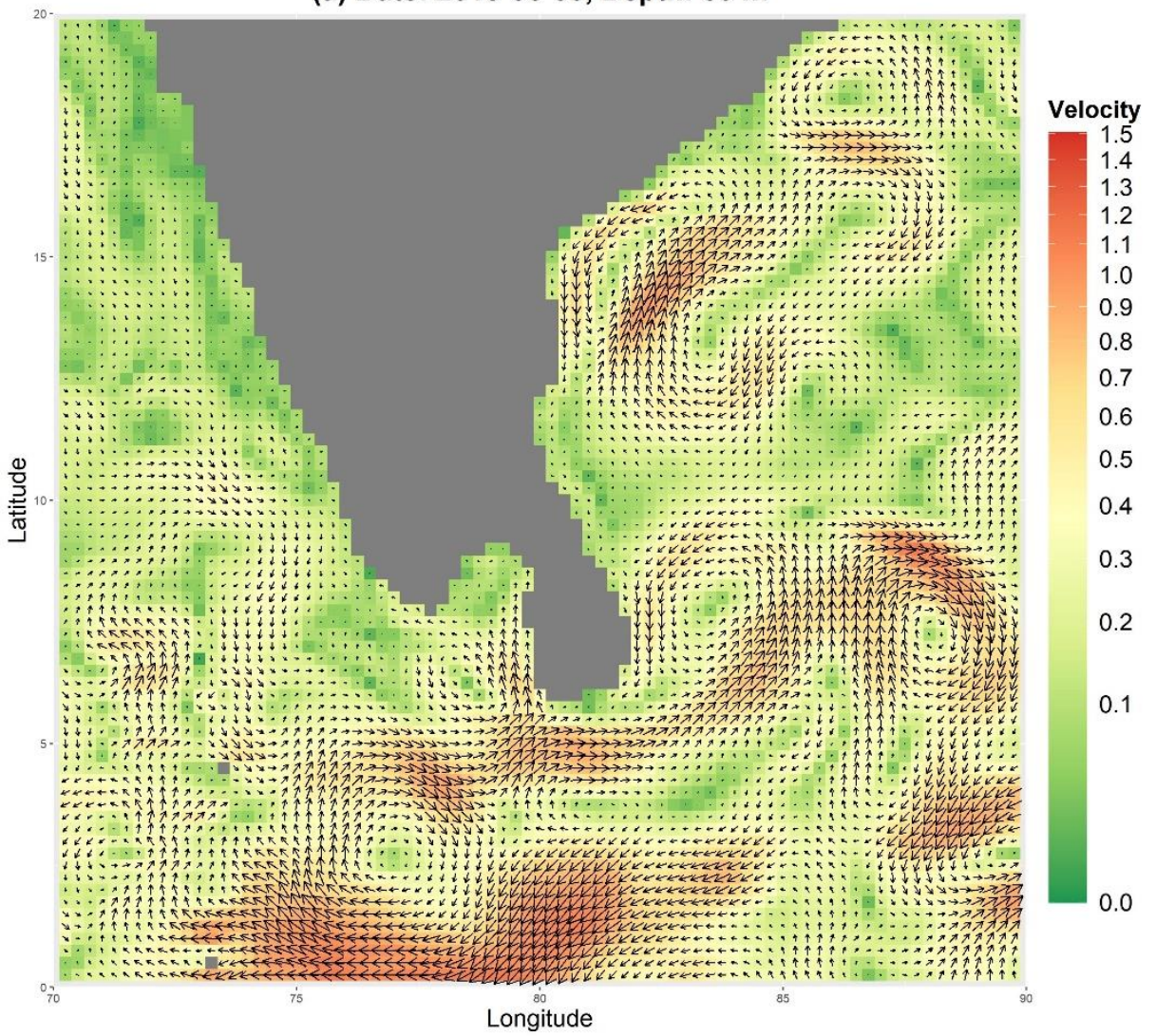

(b) Date: 2018-06-30, Depth: 75 m

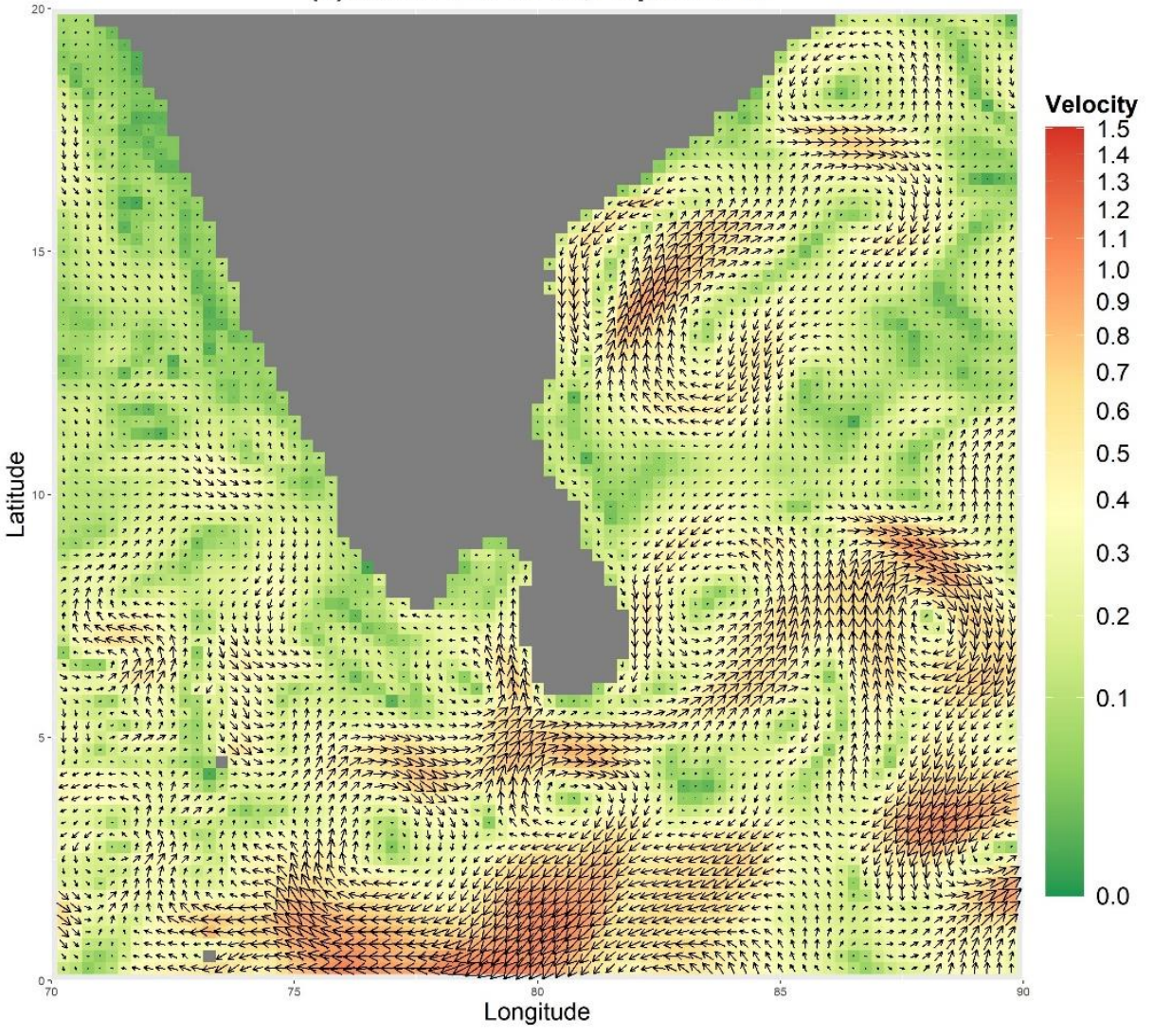

Figure 12: Current maps during the southwest monsoon at $60 \mathrm{~m}$ and $75 \mathrm{~m}$ depths. 


\section{DISCUSSION}

Spatial distribution of Yellowfin tuna in the study area is not randomly distributed. They tend to aggregate within preferred environmental conditions. Tuna species are highly sensitive to environmental changes. Each species is characteristic of a particular habitat, which is mainly determined by temperature and oxygen concentration. The warming of the surface ocean reduces the solubility of oxygen in the surface ocean, which decreases the sea surface dissolved oxygen (Matear et al., 2000). If the water temperature exceeds the thermal tolerance or oxygen concentration is insufficient to maintain physiological requirements, the tuna will move to different latitudes, longitudes and depths.

As the depth increases, YFT can be found at relatively low temperature ranges. The results of this study also confirms that YFT is more likely to be aggregated at the depth range from $60-75 \mathrm{~m}$ in the study area. The current velocity in the surface layer is ranging from about $0.0-1.0 \mathrm{~ms}^{-1}$. However, more catch rates were recorded at low current speed that was less than $0.4 \mathrm{~ms}^{-1}$, and the peak was around $0.25 \mathrm{~ms}^{-1}$. Adult Yellowfin tuna spent $\simeq 60 \%$ to $80 \%$ of their time immediately below the mixed surface-layer, less than $100 \mathrm{~m}$ (Brill et al., 1999). Thus, it can be concluded that the vertical migration of tuna species is associated with the thermocline. The prediction of fishing depth based on the vertical temperature structure is an essential parameter for successful fishing operations. Higher tuna catch rates can be obtained by maintaining the longlining depth based on the seasonal variation of temperature and currents in space and time.

Shape of the vertical temperature profile depends on the season and the location. The thermocline fluctuates between 60 - $160 \mathrm{~m}$ seasonally. The result also confirms the changes in current pattern around Sri Lankan waters during two monsoon periods. The southwest monsoon currents flows along the southern coast of Sri Lanka from west to east. During the northeast monsoon, the currents reverse its direction (De Vos et al., 2014). Sri Lankan Dome (SLD) is located to the east of Sri Lanka during the southwest monsoon. SLD is normally formed in June then migrates towards north when the season goes away from that region. Current changes its direction and speed over the time and depth. Currents generally diminish in intensity with increasing depth (Gordon and Cenedese, 2021). These changes in ocean are induced by climate change therefore have important implications for the distribution and abundance of tuna species as they are very sensitive to oceanographic conditions.

\section{CONCLUSION}

The results show that Yellowfin tuna prefers warmer waters, above $24^{\circ} \mathrm{C}$, particularly fished at the temperature between $22.0-27.0^{\circ} \mathrm{C}$ and current speed less than $0.4 \mathrm{~ms}^{-1}$, peak around $0.25 \mathrm{~ms}^{-1}$. The seasonal variability of vertical temperature of the thermocline fluctuates between $60-160 \mathrm{~m}$ depth. The result of the study also confirms that tuna is more likely to be aggregated at the depth range of $60-75 \mathrm{~m}$. The Yellowfin tuna fishable aggregations are available in the area throughout the year although the spatial distribution of Yellowfin tuna is varying depending on the prevailing oceanographic conditions. Thus, the prediction of fishing depth based on the vertical temperature structure and the current pattern is an essential parameters for successful fishing operations.

\section{REFERENCES}

[1] Jayasooriya, J.A.D.B. and Bandara, H.M.U. (2013). Analysis of Catch Assessment of Tuna Fisheries in Sri Lanka. Ministry of Fisheries and Aquatic Resources Development Sri Lanka (October), 23-28.

[2] Lecomte, M., Rochette, J., Laurans, Y. and Iddri, R.L. (2017). Indian Ocean tuna fisheries : between development opportunities and sustainability issues. (June), 1-96.

[3] Zagaglia, C. R., Lorenzzetti, J. A. and Stech, J. L. (2004). Remote sensing data and longline catches of yellowfin tuna (Thunnus albacares) in the equatorial Atlantic. Remote Sensing of Environment 93(1-2), 267-281.

[4] Rajapaksha, J. (2009). Evaluation and improvements of a satellite based forecast system for sri lankan yellowfin tuna fishery. United Nations University Fisheries Training Programme, Iceland.

[5] De Vos, A., Pattiaratchi, C. B. and Wijeratne, E. M. S. (2014a). Surface circulation and upwelling patterns around Sri Lanka. Biogeosciences 11 (20), 5909-5930.

[6] Rajapaksha, J. K. (2014). Multispectral Satellite Data on Ocean Surface to Predict its Vertical Temperature Profiles, A Simple Model. Asian Journal of Geoinformatics 14(4).

[7] Hays, G. C. (2017). Ocean currents and marine life. Current Biology 27 (11), R470-R473.

[8] Rajeesh, R. and Dwarakish, G. S. (2015). Satellite Oceanography- A review. Aquatic Procedia 4(Icwrcoe), $165-172$.

[9] Klemas, V. (2013). Fisheries applications of remote sensing: An overview. Fisheries Research 148, $124-136$.

[10] Rajapaksha, J. K., Samarakoon, L. and Gunathilaka, A. A. J. K. (2013). Environmental Preferences of Yellowfin Tuna in the North East Indian Ocean: An Application of Satellite Data to Longline Catches Improvement of Tuna fishing ground forecast system of NARA View project Engineering Geological, Hydrogeological, and Geotechnical. International Journal This publication is licensed under Creative Commons Attribution CC BY. 


$$
\text { of Fisheries and Aqauatic Sciences 2(4), 72-80. }
$$

[11] Copernicus Marine Environment Monitoring Service. [Online]. Available: https://marine.copernicus.eu/.

[12] Gomez-Rubio, V. (2018). Generalized Additive Models: An Introduction with R (2nd Edition). Journal of Statistical Software 86 (Book Review 1), 1-5.

[13] Andrade H. A. and Garcia, C. A. E. (1999). Skipjack tuna fishery in relation to sea surface temperature off the southern Brazilian coast. Fisheries oceanography 8(4), 245-254.

[14] Zainuddin, M. (2011) Skipjack Tuna in Relation To Sea Surface Temperature and Chlorophyll-a Concentration of Bone Bay Using Remotely Sensed Satellite Data. Jurnal Ilmu dan Teknologi Kelautan Tropis 3(1).

[15] Wood, S. N. (2001). GAMs and generalized ridge regression for R. R News 1, 20-25.

[16] Rathnasuriya, M. I. G., Gunasekara, S. S., Haputhanthri, S. S. K. and Rajapaksha, J. K. (2016). Environmental preferences of Billfish in Bay of Bengal: A case study in longline fishery of Sri Lanka. IOTC-WPB14-2016-10, Rev1.

[17] Department of Meterology, Sri Lanka. Climate of Sri Lanka. Available at: http://www.meteo.gov.lk/.

[18] Odd Henrik, S. and Aas, E. (2012). Lecture notes in physical oceanography.

[19] Yapa, K. K. A. S. (2011). Upwelling phenomena in the southern coastal waters of Sri Lanka during southwest monsoon period as seen from MODIS. Sri Lankan Journal of Physics 10(0).

[20] Brill, R. W., Block, B. A., Boggs, C.H., Bigelow, K. A., Freund, E. V. and Marcinek, D. J. (1999). Horizontal movements and depth distribution of large adult yellowfin tuna (Thunnus albacares) near the Hawaiian Islands, recorded using ultrasonic telemetry: implications for the physiological ecology of pelagic fishes. Marine Biology 133 (3), 395-408.

[21] Gordon A. L. and Cenedese, C. (2021). Ocean Current. Encyclopedia Britannica.

\section{AUTHORS}

First Author - Maddumage Upeksha Swarnamalie, Postgraduate Institute of Science, University of Peradeniya, P.O. Box 25, Peradeniya, Sri Lanka, upeksha.s.maddumage@gmail.com.

Second Author - Jagath Rajapaksha, Senior Lecturer, Department of Oceanography, The Ocean University of Sri Lanka, Colombo 15, Sri Lanka, jagath_r@hotmail.com.

Third Author - Jagath Gunatilake, Senior Lecturer, Department of Geology, University of Peradeniya, Peradeniya, jagathpgis@gmail.com.

Corresponding Author - Maddumage Upeksha Swarnamalie, upeksha.s.maddumage@gmail.com. 